\title{
Dietary effects of introducing school meals based on the New Nordic Diet - a randomised controlled trial in Danish children. The OPUS School Meal Study
}

\author{
Rikke Andersen $^{1 *}$, Anja Biltoft-Jensen ${ }^{1}$, Tue Christensen ${ }^{1}$, Elisabeth W. Andersen ${ }^{2}$, Majken Ege ${ }^{1}$, \\ Anne V. Thorsen ${ }^{1}$, Stine-Mathilde Dalskov ${ }^{3}$, Camilla T. Damsgaard ${ }^{3}$, Arne Astrup ${ }^{3}$, \\ Kim F. Michaelsen ${ }^{3}$ and Inge Tetens ${ }^{1}$ \\ ${ }^{1}$ Division of Nutrition, National Food Institute, Technical University of Denmark, Mørkhøj Bygade 19, \\ Søborg 2860, Denmark \\ ${ }^{2}$ Department of Applied Mathematics and Computer Science, Technical University of Denmark, Lyngby, Denmark \\ ${ }^{3}$ Department of Nutrition, Exercise and Sports, Faculty of Science, University of Copenhagen, Frederiksberg, Denmark.
}

(Submitted 3 July 2013 - Final revision received 3 February 2014 - Accepted 4 February 2014 - First published online 8 April 2014)

\section{Abstract}

The OPUS (Optimal well-being, development and health for Danish children through a healthy New Nordic Diet (NND)) School Meal Study investigated the effects on the intake of foods and nutrients of introducing school meals based on the principles of the NND covering lunch and all snacks during the school day in a cluster-randomised cross-over design. For two 3-month periods, 834 Danish children aged 8-11 years from forty-six school classes at nine schools received NND school meals or their usual packed lunches brought from home (control) in random order. The whole diet of the children was recorded over seven consecutive days using a validated Web-based Dietary Assessment Software for Children. The NND resulted in higher intakes of potatoes (130\%, $95 \%$ CI 2.07, 2.58), fish (48\%, $95 \%$ CI $1 \cdot 33,1 \cdot 65$ ), cheese $(25 \%, 95 \%$ CI 1·15, 1·36), vegetables (16\%, $95 \%$ CI 1·10,1·21), eggs (10\%, 95\% CI 1.01, 1·19) and beverages (6\%, $95 \%$ CI $1 \cdot 02$, $1.09)$, and lower intakes of bread (13\%, $95 \%$ CI $0.84,0.89)$ and fats $(6 \%, 95 \%$ CI $0.90,0.98)$ were found among the children during the NND period than in the control period (all, $P<0 \cdot 05$ ). No difference was found in mean energy intake $(P=0 \cdot 4)$, but on average children reported $0.9 \%$ less energy intake from fat and $0.9 \%$ higher energy intake from protein during the NND period than in the control period. For micronutrient intakes, the largest differences were found for vitamin D ( $42 \%, 95 \%$ CI 1.32, 1.53) and iodine (11\%, 95\% CI $1.08,1.15)$ due to the higher fish intake. In conclusion, the present study showed that the overall dietary intake at the food and nutrient levels was improved among children aged 8-11 years when their habitual packed lunches were replaced by school meals following the principles of the NND.

Key words: Interactive Web-based dietary assessments: Children: New Nordic Diet: School meal interventions

Life style-related diseases seem to be initiated in childhood ${ }^{(1)}$, and since diet affects the health, growth and development of children to a large extent ${ }^{(2)}$, the diet of children is important.

The Danish National Survey of Diet and Physical Activity (DANSDA) 2003-8 showed that the overall diet of Danish children contains too many energy-dense, nutrient-poor foods, too much sugar, salt, fat and saturated fat, and too little dietary fibre, fruit and vegetables, and fish ${ }^{(3)}$. The same picture is found when looking at the intake on weekdays only ${ }^{(4,5)}$. A report has suggested that the intake of fish, fruit and vegetables should be increased and that the intake of high-fat meat products should be replaced with lean meat products in the lunch meals of Danish children. The report has also suggested that children's sugar-rich snack meals should be replaced by fruit, vegetables and whole-grain products $^{(5)}$. A similar picture was found in the UK, where Evans et $a l .{ }^{(6)}$ in a cross-sectional survey found that few packed lunches meet the UK school meal standards.

Danish children have been reported to consume $40-45 \%$ of their daily energy intake during school hours and after-school activities $^{(7)}$. Denmark has no national school food programme, and $75 \%$ of Danish school children aged $7-10$ years bring a packed lunch from home, usually based on open sandwiches with Danish rye bread ${ }^{(4)}$. The topping is usually sliced meat products and liver paste. Fruit and, to a lesser extent, vegetables are also brought from home ${ }^{(4)}$. Most Danish schools (95\%)

Abbreviations: AR, acceptable reporters; NND, New Nordic Diet; OR, over-reporters; UR, under-reporters; WebDASC, Web-based Dietary Assessment Software for Children.

*Corresponding author: Dr R. Andersen, fax +453588 71 19, email rian@food.dtu.dk 
subscribe to a milk service and a few schools (0.2\%) have vending machines with sugar-sweetened beverages ${ }^{(8)}$.

Since children spend more time in schools than in any other environment away from home, schools provide an excellent setting for public health nutritional interventions that will reach all children regardless of ethnic and socio-economic background $^{(7,9,10)}$. Social differences in overweight and obesity, especially among boys of parents with low education, have widened in Denmark ${ }^{(11)}$. Since establishing healthy eating patterns in childhood has greater prevention potential than changes later in life ${ }^{(12-14)}$, establishing healthy dietary habits should start in childhood.

The OPUS School Meal Study was part of the Danish research project OPUS (Optimal well-being, development and health for Danish children through a healthy New Nordic Diet (NND) $)^{(7)}$. The aim of the present part of the OPUS School Meal Study was to assess the impact of serving school meals based on the principles of the NND compared with the usual packed lunches on dietary intake and nutrient status. The effect of the NND on growth, early disease risk markers, well-being and absence from school, cognitive function, food waste and cost, as well as social and cultural features has been investigated by other research groups.

Unlike the OPUS School Meal Study, most published school intervention studies have been multi-component studies, in which changes in existing school meals are combined with physical activity and/or nutritional education ${ }^{(15-24)}$ often focusing on the prevention of obesity in children ${ }^{(9,16,20,23,25-28)}$. Other school meal interventions have increased fruit and vegetable intake as the main focus ${ }^{(29-32)}$. In just a few studies, professional chefs have been hired to train cafeteria staff in providing healthier, more palatable school meals. One example is a recent pilot study that aimed at replacing trans and saturated fats with unsaturated fats, reducing added sugar and salt, and increasing whole grains and fibre intake as well as improving the palatability of the meals, and most of these aims were achieved ${ }^{(33)}$.

To our knowledge, no randomised controlled trials have assessed the impact of introducing a full-meal concept with recipes and menus developed by chefs to ensure the gastronomic potential of the food covering lunch and all snacks during the school day, as well as measuring children's dietary intake, dietary and nutrient status, physical activity, health and cognitive function ${ }^{(7)}$.

The aim of the present study was to investigate the effects of serving NND school meals compared with the usual packed lunches on the dietary intake at the food level, and on the average energy, macro- and micronutrient intakes of the 834 Danish children aged 8-11 years who took part in the OPUS School Meal Study.

\section{Subjects and methods}

\section{Design}

The OPUS School Meal Study was a cluster-randomised, controlled, unblinded, cross-over study. For two 3-month periods during the school year 2011-2, children received school meals based on the NND or their usual packed lunches (control) in random order. The overall study design has been described in more detail previously ${ }^{(7)}$. Written informed consent was obtained from all parents/guardians of the children. The study protocol was approved by the Danish National Committee on Biomedical Research Ethics (H-1-2010-124). The trial was registered in the database www.clinicaltrials.gov (no. NCT 01457794) ${ }^{(7)}$.

\section{Subjects}

The initial contact was established with thirty-nine schools from the eastern part of Denmark (Zealand and LollandFalster). Children from forty-six school classes (3rd and 4th grades) at nine Danish schools were invited to participate in the OPUS School Meal Study. The inclusion criteria for each school have been described elsewhere ${ }^{(7)}$. Exclusion criteria for the children were diseases or conditions that might obstruct the measurements or put the children at risk if eating the OPUS school diet (e.g. due to nutrient malabsorption or food allergies). The recruitment procedure, inclusion and exclusion criteria have been described in more detail elsewhere $^{(7)}$. In total, 834 children were included in the baseline part of the study.

\section{Background information}

At baseline, each child accompanied by at least one parent or guardian underwent a $2 \mathrm{~h}$ in-depth interview by a trained interviewer (including instructions on how to use the dietary assessment tool), either at the school or at home ${ }^{(7)}$. The educational level of the household was categorised according to the standard classifications of Statistics Denmark, i.e. as the highest level of education achieved by a parent in the household. The variable was divided into six different groups depending on the educational level (lower secondary education, upper secondary education or equivalent, vocational education, short higher education, Bachelor's degree or equivalent, Master's degree or higher education).

\section{Dietary intervention}

During the 3-month NND intervention period, the children were offered a mid-morning snack, an ad libitum hot lunch meal and an afternoon snack served in a small bag ${ }^{(7)}$. The meals were free of charge for all the children in the invited school classes, regardless of their participation in the study, and they were produced locally at each school by trained chefs and kitchen personnel hired for the study. Small groups of four to six children took part in the cooking every day. The snacks and lunch meals were designed to cover $40-45 \%$ of the daily energy intake based on the energy requirement of an 11-year-old boy ${ }^{(5,34)}$. A 3-week menu was developed for each of the three seasons (autumn, winter and spring) and was served repeatedly during the season. The menus complied with the principles of the $\mathrm{NND}^{(7,35,36)}$. Each week, the menu plan was: Monday soup, Tuesday meat, Wednesday vegetarian, Thursday fish and a buffet day 
on Fridays consisting of pre-made leftovers from the four 1st days of the week ${ }^{(7)}$. During the 3-month control period, the children brought their usual packed lunches from home. The typical packed lunch consists of open Danish rye bread sandwiches with various toppings, such as sliced meat products, chocolate spread and liver paste, and fruit and/or vegetables $^{(4)}$. Water was served with the NND lunch, but children with milk subscriptions continued to have their milk as usual.

\section{Dietary assessment}

The whole diet of the children was recorded over seven consecutive days using an interactive Web-based Dietary Assessment Software for Children (WebDASC) developed for the purpose and validated during the OPUS pilot study ${ }^{(37-39)}$. Briefly, WebDASC is a self-administered Internet-based interactive food record tool for use by children aged 8-11 years with or without support from their parents, completed at the end of the day. The parents and children were instructed on how to use the dietary assessment tool by a trained interviewer before the study. Reminder emails were sent to the parents if the dietary assessments were not completed on a daily basis during the assessment periods, reminder telephone calls were made when dietary assessment was not initiated, and a telephone hotline was available for the families at all times in case of questions. The dietary assessment was recorded during the weeks before the clinical measurements as described elsewhere ${ }^{(7)}$, and included a baseline measurement and measurements at the end of the first and at the end of the second dietary intervention period. Since the schools joined the study one by one, the first dietary assessment started between August and November 2011, and data collection ended in June 2012. Children without access to a computer or the Internet filled in a paper version of a $7 \mathrm{~d}$ pre-coded food record based on the food-record used in the DANSDA 2003-8 ${ }^{(3)}$.

\section{Estimation of dietary intake}

The intake data were processed by the in-house-developed General Intake Estimation System, a system originally developed for the DANSDA ${ }^{(3)}$, which interpreted the recorded consumption into the ingredients that form the basis for the further calculations and estimations of intake of food, energy and nutrients for each individual. For these calculations, intakes were directly collected by querying the WebDASC data tables. The General Intake Estimation System used recipes developed for the WebDASC covering both ordinary and OPUS foods. The nutrient data were obtained from the Danish Food Composition Databank, revision $7^{(40)}$, supplied with data compiled in-house for the new Nordic foods. Dietary intake was estimated for each child as an average of the days recorded. Dietary intake was estimated for thirteen food groups, energy intake, energy distribution, nine macronutrients and nineteen micronutrients (ten vitamins and nine minerals).

Energy density was calculated as energy (kJ) divided by weight $(\mathrm{g})$ for food and beverages separately. Food was defined as solid food and liquids consumed as food (e.g. soups and yogurt). Beverages were defined as either energy-containing (e.g. milk, sweetened drinks and juice) or non-energy-containing (e.g. water and artificially sweetened drinks).

\section{Under-, acceptable and over-reporters}

Under-reporters (UR), acceptable reporters (AR) and overreporters (OR) were determined by the subjects' EI:BMR ratio (EI; mean reported energy intake) and classified by cut-offs suggested by Black $^{(41)}$ as follows: EI:BMR $\leq 1.05$ for UR, $\mathrm{EI}: \mathrm{BMR}=1 \cdot 06-2 \cdot 27$ for $\mathrm{AR}$ and $\mathrm{EI}: \mathrm{BMR} \geq 2 \cdot 28$ for $\mathrm{OR}$, using a physical activity level of $1 \cdot 55$. The BMR was calculated from descriptive equations (Oxford prediction) using height, weight, sex and age ${ }^{(42)}$.

\section{Statistical analysis}

Analyses included standard descriptive statistics. All means and medians include both eaters and non-eaters (with zero intakes).

Hierarchical mixed models were used to investigate the effect of eating the NND compared with the control separately for all food groups, energy intake, energy distributions, energy density, micro- and macronutrients. Since the children were nested in classes, and the classes were nested in schools, the models included three random effects (child, class and school). The models also included fixed effects: sex (boy and girl); grade (3rd and 4th); season (autumn, winter and spring), BMI (in four groups of approximately similar size: BMI $\leq 15.6 \mathrm{~kg} / \mathrm{m}^{2}$, $15.6<\mathrm{BMI} \leq 16.6 \mathrm{~kg} / \mathrm{m}^{2}, \quad 16.6<\mathrm{BMI} \leq 18.6 \mathrm{~kg} / \mathrm{m}^{2} \quad$ and BMI $>18.6 \mathrm{~kg} / \mathrm{m}^{2}$ ); diet (packed lunch and NND); dietary period; household education (lower secondary education, upper secondary education or equivalent, vocational education, short higher education, Bachelor's degree or equivalent, Master's degree or higher education).

Possible carry-over effects were tested by the interaction between diet and dietary period, allowing for different effects of the NND in the first and second dietary periods.

Some children had zero intakes of some of the food groups (e.g. cheese, potatoes, poultry or fish), which means that the assumptions behind the normal models are not fulfilled, and these semi-continuous outcomes were therefore analysed in two steps ${ }^{(43)}$ : first, a logistic regression model with random effects for the binary outcome (intake $v$. no intake) giving the odds of having a zero intake, and then the abovementioned hierarchical mixed model for the continuous outcome for the children with a positive intake only.

In separate hierarchical mixed models, the effect of reporting (UR, OR and AR) was included together with sex (boy and girl), grade (3rd and 4th), diet (packed lunch and NND) and dietary period. The main reason for this was to see whether the effect of diet was influenced by this change in the model.

A separate hierarchical mixed model was also used to test whether children who dropped out of the study differed from the rest of the children with regard to energy intake and energy distributions at baseline.

The assumptions underlying the models were tested using residual plots and quartile-quartile (QQ) plots. 
The outcomes were all continuous variables, and most variables (all food groups, all micronutrients and dietary fibre) were transformed using the natural logarithm $\left(\log _{2}\right)$. All transformed variables were back-transformed using the anti-log when presenting the results.

All statistical analyses were performed using SAS version 9.3 (SAS Institute, Inc.). The significance level chosen was $P<0 \cdot 05$.

\section{Results}

In total, 834 children were included in the present study: 798 (95.7\%) completed the first dietary assessment sufficiently (intake registered $4-7 \mathrm{~d}$ ), twenty-six completed the dietary assessment insufficiently $(0-3 \mathrm{~d})$ and ten dropped out; 741 (88.8\%) completed the second dietary assessment sufficiently, thirty completed the dietary assessment insufficiently and twenty-seven dropped out; and 663 (79.5\%) completed the third dietary assessment sufficiently, forty-nine completed the dietary assessment insufficiently and thirty-one dropped out. During the first, second and third dietary assessments, six, five and four children used the paper version, respectively. The baseline characteristics of the children included are shown in Table 1. All results are based on average total daily intakes.

\section{Carry-over effects}

For most variables, no carry-over effect of the dietary period was observed. A carry-over effect was found for vitamin $\mathrm{D}$ $(P=0 \cdot 007)$, vitamin $\mathrm{E}(P=0.04)$ and vitamin $\mathrm{C}(P=0.02)$, but this was found to be due to seasonal variation, because the carry-over effect disappeared when we adjusted for seasonal variation $(P=0 \cdot 3,0 \cdot 7$ and $0 \cdot 8$, respectively).

\section{Effects of the New Nordic Diet on the intake of food groups}

All children reported consuming milk, bread and other cereals, vegetables, fruit, meat, eggs, fats, sugar and candy, and beverages (excluding milk) on a daily basis. However, certain food groups (cheese, potatoes, poultry and fish) were not eaten by all children during the control and intervention periods (Table 2). The children had significantly higher odds of eating cheese (OR 2.66, 95\% CI 1.24, 5.68), potatoes (OR 16.2, $95 \%$ CI 3.84, 68.39) and fish (OR 3.79, $95 \%$ CI $2 \cdot 80,5 \cdot 15)$

Table 1. Baseline characteristics of the children included in the study (Mean values and standard deviations)

\begin{tabular}{|c|c|c|c|c|c|c|}
\hline & \multicolumn{2}{|c|}{ All (n 798) } & \multicolumn{2}{|c|}{ Boys ( $n$ 471) } & \multicolumn{2}{|c|}{ Girls ( $n$ 381) } \\
\hline & Mean & SD & Mean & SD & Mean & SD \\
\hline$\%$ & \multicolumn{2}{|c|}{100} & \multicolumn{2}{|c|}{$52 \cdot 3$} & \multicolumn{2}{|c|}{$47 \cdot 7$} \\
\hline Age (years) & 9.98 & 0.6 & $10 \cdot 4$ & 0.6 & 9.9 & 0.6 \\
\hline Weight $(\mathrm{kg})^{*}$ & 35.0 & $7 \cdot 1$ & 35.4 & $7 \cdot 2$ & 34.7 & 6.9 \\
\hline Height $(\mathrm{cm}) \dagger$ & 142.5 & $7 \cdot 1$ & $142 \cdot 7$ & $7 \cdot 2$ & $142 \cdot 1$ & $7 \cdot 0$ \\
\hline BMI $\left(\mathrm{kg} / \mathrm{m}^{2}\right)^{*}$ & $17 \cdot 1$ & $2 \cdot 4$ & $17 \cdot 2$ & 2.4 & $17 \cdot 1$ & $2 \cdot 4$ \\
\hline
\end{tabular}

during the NND period than in the control period, but this was not the case for poultry $(P=0 \cdot 23)$ (Table 3$)$.

Among the consumers (intake above zero), significantly $(P<0.0001)$ higher intakes ( $\%$ increase) of potatoes and potato products $(130 \%, 95 \%$ CI $2 \cdot 07,2 \cdot 58)$, fish and fish products ( $48 \%$, $95 \%$ CI $1.33,1.65)$, cheese and cheese products $(25 \%, 95 \%$ CI $1 \cdot 15,1 \cdot 36)$, vegetable and vegetable products (16\%, 95\% CI $1 \cdot 10$, $1 \cdot 21)$ and eggs (10\%, 95\% CI 1.01, 1.19), as well as beverages (excluding milk) $(P=0.0004)(6 \%, 95 \%$ CI $1.02,1.09)$ were reported during the NND period than in the control period. Significantly lower intakes (\% decrease) of bread and other cereal products $(13 \%, 95 \%$ CI $0.84,0.89 ; P<0.0001)$ and of fats ( $6 \%, 95 \% \mathrm{CI} 0 \cdot 90,0 \cdot 98 ; P=0 \cdot 006)$ were reported during the NND period than in the control period (Table 3 ). No differences in the reported intake of milk and milk products $(P=0.87)$, fruit and fruit products $(P=0.46)$, meat and meat products $(P=0 \cdot 66)$, poultry and poultry products $(P=0 \cdot 42)$ or sugar and candy $(P=0 \cdot 29)$ were found between the two periods (Table 3 ).

\section{Effect of the New Nordic Diet on energy intake, energy distributions and energy densities}

No difference was found in the average energy intake per $\mathrm{d}$ between the NND and control periods $(P=0 \cdot 44)$ (Table 4). However, the energy density from food $(P<0.0001)$ and beverages $(P=0 \cdot 001)$ was lower during the NND period than in the control period. On average, energy density was $0.5 \mathrm{~kJ} / \mathrm{g}$ less from food and $0.04 \mathrm{~kJ} / \mathrm{g}$ less from beverages during the NND period than in the control period (Table 4). Finally, the energy distributions from fat and protein were both statistically different $(P<0.0001)$ between the two periods, with children reporting on average $0.9 \%$ lower energy intake from fat and $0.9 \%$ higher energy intake from protein during the NND period than in the control period with packed lunches. No differences in energy distribution from carbohydrate and added sugar were found between the two periods $(P=0.72$ and 0.56) (Table 4).

\section{Effect of the New Nordic Diet on the intake of macronutrients}

Children reported a significantly lower average daily intake of total fat (2.4 g, $P=0.0007)$, saturated fat ( $1.3 \mathrm{~g}, P<0.0001)$, monounsaturated fat $(0.7 \mathrm{~g}, P=0.01)$ and trans-fatty acid $(0.05 \mathrm{~g}$, $P=0.02)$ during the NND period than in the control period, and they reported an average higher daily intake of protein $(3.4 \mathrm{~g}$, $P<0.0001$ ) (Table 4). The intake of dietary fibre was borderline significantly higher during the NND period than in the control period $(P=0.05)$. No differences in the intake of polyunsaturated fat $(P=0.82)$, carbohydrate $(P=0 \cdot 71)$ and added sugar $(P=0 \cdot 27)$ were found between the two periods (Table 4).

\section{Effect of the New Nordic Diet on the intake of micronutrients}

For the majority of the micronutrients, the NND period resulted in higher reported average daily intakes than in the control period with packed lunches (Table 5). 
Table 2. Median daily food intakes in children during the control period with packed lunches and during the intervention period with New Nordic Diet (NND) lunches (Median values with their 10th and 90th percentiles)

\begin{tabular}{|c|c|c|c|c|c|c|}
\hline \multirow[b]{3}{*}{ Food group $(\mathrm{g} / \mathrm{d})$} & \multicolumn{3}{|c|}{ Control $(n$ 704) } & \multicolumn{3}{|c|}{$\operatorname{NND}\left(n 700^{\star}\right)$} \\
\hline & \multirow[b]{2}{*}{ Median } & \multicolumn{2}{|c|}{ Percentile } & \multirow[b]{2}{*}{ Median } & \multicolumn{2}{|c|}{ Percentile } \\
\hline & & 10 & 90 & & 10 & 90 \\
\hline Milk and milk products & 322 & 104 & 609 & 323 & 113 & 650 \\
\hline Cheese and cheese products & 17 & 4 & 40 & 22 & 5 & 50 \\
\hline Bread and other cereal products & 193 & 130 & 283 & 170 & 104 & 248 \\
\hline Potatoes and potato products & 37 & $2 \cdot 4$ & 100 & 82 & 26 & 176 \\
\hline Vegetables and vegetable products & 112 & 45 & 207 & 126 & 60 & 227 \\
\hline Fruit and fruit products & 114 & 28 & 244 & 103 & 36 & 239 \\
\hline Meat and meat products & 88 & 39 & 161 & 88 & 38 & 163 \\
\hline Poultry and poultry products & 17 & 0 & 55 & 17 & 0 & 52 \\
\hline Total fish and fish products & 9 & 0 & 50 & 22 & 1 & 64 \\
\hline Fat fish and fish products & 0 & 0 & 29 & 5 & 0 & 36 \\
\hline Lean fish and fish products & 3 & 0 & 27 & 10 & 0 & 41 \\
\hline Eggs & 14 & 3 & 37 & 16 & 5 & 37 \\
\hline Fats & 23 & 10 & 41 & 21 & 10 & 37 \\
\hline Sugar and candy & 40 & 14 & 77 & 41 & 13 & 78 \\
\hline Beveragest & 692 & 346 & 1161 & 720 & 367 & 1257 \\
\hline
\end{tabular}

${ }^{*} n 699$ for milk and milk products.

†Excluding milk.

The largest effect was found in the intake of vitamin D $(P<0.0001)$, with a $42 \%$ higher intake during the NND period than in the control period. The children reported 5-8\% higher intakes of vitamin $\mathrm{E}(P<0 \cdot 0001)$, niacin $(P<0 \cdot 0001)$, vitamin $\mathrm{B}_{6}(P<0.0001)$, folate $(P=0.0006)$ and vitamin $\mathrm{C}(P=0.0003)$ during the NND period than in the control period. No differences were found in the intakes of vitamin $\mathrm{A}(P=0.32), \mathrm{B}_{1}$ $(P=0 \cdot 16), \mathrm{B}_{2}(P=0.70)$ and $\mathrm{B}_{12}(P=0.07)$ (Table 5$)$.
The largest difference in the intake of minerals between the NND and control periods was found for the intake of iodine $(P<0 \cdot 0001)$, where the intake in the NND period was $11 \%$ higher than that in the control period with packed lunches. The average reported intakes of $\mathrm{P}(P<0.0001), \mathrm{Mg}(P=0.002), \mathrm{Fe}(P<0.0001)$, Se $(P<0.0001)$ and $\mathrm{K}(P<0.0001)$ were $3-8 \%$ higher during the NND period than in the control period. The intake of $\mathrm{Zn}$ was borderline significantly higher during the NND period than in

Table 3. OR of non-zero intakes for the New Nordic Diet (NND) compared with packed lunch (model 1) and the effect of the NND on food groups compared with the control (model 2)

(Odds ratios or estimates and $95 \%$ confidence intervals)

\begin{tabular}{|c|c|c|c|c|c|c|c|c|}
\hline & \multicolumn{4}{|c|}{ Model $1^{*}$} & \multicolumn{4}{|c|}{ Model 2† } \\
\hline & $n$ & $P$ & OR & $95 \% \mathrm{Cl}$ & $n$ & $P$ & Estimate & $95 \% \mathrm{Cl}$ \\
\hline Milk and milk products & - & - & - & - & 745 & 0.87 & 1.00 & $0.95,1.04$ \\
\hline Cheese and cheese products & 750 & 0.012 & $2 \cdot 66$ & $1 \cdot 24,5 \cdot 68$ & 740 & $<0.0001$ & 1.25 & $1 \cdot 15,1.36$ \\
\hline Bread and other cereal products & - & - & - & - & 745 & $<0.0001$ & 0.87 & $0.84,0.89$ \\
\hline Potatoes and potato products & 750 & 0.0002 & $16 \cdot 2$ & $3 \cdot 84,68 \cdot 39$ & 742 & $<0.0001$ & $2 \cdot 31$ & $2 \cdot 07,2.58$ \\
\hline Vegetables and vegetable products & - & - & - & - & 745 & $<0.0001$ & $1 \cdot 16$ & $1 \cdot 10,1 \cdot 21$ \\
\hline Fruit and fruit products & - & - & - & - & 745 & 0.46 & 0.97 & $0.91,1.04$ \\
\hline Meat and meat products & - & - & - & - & 745 & 0.66 & 0.99 & $0.94,1.04$ \\
\hline Poultry and poultry products & 750 & 0.23 & 0.85 & $0.65,1.11$ & 695 & 0.42 & 1.05 & $0.94,1.17$ \\
\hline Total fish and fish products & 750 & $<0.0001$ & 3.79 & $2 \cdot 80,5 \cdot 15$ & 691 & $<0.0001$ & 1.48 & $1.33,1.65$ \\
\hline Fat fish and fish products & 750 & $<0.0001$ & 1.61 & $1.29,1.99$ & 522 & 0.02 & 1.19 & $1.03,1.38$ \\
\hline Lean fish and fish products & 750 & $<0.0001$ & $1 \cdot 87$ & $1.49,2.34$ & 612 & $<0.0001$ & 1.47 & $1.30,1.65$ \\
\hline Eggs & - & - & - & - & 745 & 0.03 & $1 \cdot 10$ & $1.01,1.19$ \\
\hline Fats & - & - & - & - & 745 & 0.006 & 0.94 & $0.90,0.98$ \\
\hline Sugar and candy & - & - & - & - & 744 & 0.29 & 0.97 & $0.91,1.03$ \\
\hline Beverages§ & - & - & - & - & 745 & 0.0004 & 1.06 & $1.02,1.09$ \\
\hline
\end{tabular}

$n$, number of children who contributed to the analyses.

* Model 1 includes children with zero intakes. Analysed by logistic regression models for the binary outcome (intake $v$. no intake) with random effects to take the design into account. The analyses were carried out for the food groups for which the children had a zero intake, controlling for sex, grade and dietary period (the OR of non-zero intakes in the NND group compared with packed lunch).

† Model 2 includes children with intakes greater than zero. Analysed by hierarchical mixed models, controlling for random effects (child, class and school) and fixed effects (sex, grade, dietary period, BMI, season eating the NND and household education).

$\ddagger$ All food groups were $\log _{2}$ transformed; hence estimates are expressed in percentages.

§Excluding milk. 
the control period $(P=0.05)$. No differences in the intakes of $\mathrm{Ca}$ $(P=0.06)$ and $\mathrm{Na}(P=0.07)$ were found between the two periods (Table 5).

\section{Sex and grade differences}

With the exception of vitamin $\mathrm{C}$, significant sex differences $(P<0.05)$ were found between the reported intakes for all macro- and micronutrients, total energy intake and food energy density, with the girls having a lower intake than boys. The same pattern was found for several of the food groups (bread/cereals, meat, fats, sugar/candy and beverages). Fruit intake was higher in girls than in boys. However, no differences were found between boys and girls $(P>0.05)$ for the intakes of milk, cheese, potatoes, vegetables, poultry, fish and eggs, and energy density or energy intake distributions from fat, carbohydrate, added sugar and protein.

For thirteen of the nineteen micronutrients, differences were found between the children attending the 3rd and 4th grades $(P<0.05)$, with the children attending the $3 \mathrm{rd}$ grade reporting higher average intakes than those in the 4 th grade (vitamin $\mathrm{A}$, vitamin $\mathrm{B}_{1}$, vitamin $\mathrm{B}_{2}$, niacin, vitamin $\mathrm{B}_{6}$, folate, vitamin $\mathrm{B}_{12}, \mathrm{C}, \mathrm{Ca}, \mathrm{P}, \mathrm{Mg}$, Se and $\mathrm{K}$ ). There was also a borderline significant difference for milk. For the remaining variables, no differences between the children attending the 3 rd and 4th grades $(P>0.05)$ were observed.

\section{Over- and under-reporters}

In the three dietary assessments, 9-14\% of the children were classified as UR and $2-3 \%$ as OR. The effect of eating the NND on most variables was the same whether the child was an UR, an AR or an OR. However, for monounsaturated fat, trans-fatty acids and fats, the effect changed from a significant
( $P$ values shown in Tables 3 and 4 ) to a non-significant $(P>0.05)$ decrease. For vitamin $\mathrm{B}_{12}$ and $\mathrm{Ca}$, the effect of eating the NND changed from being a non-significant ( $P$ values shown in Table 5$)$ to a significant $(P<0.05)$ increase. The variables with a borderline significance (dietary fibre and $\mathrm{Zn}$; $P$ values shown in Tables 4 and 5) changed to having a significant increase.

\section{Dropouts}

Of the total children, sixty-eight dropped out of the study. Of these, fifty-five completed the dietary assessment at baseline. Their total energy intake and the energy distribution from fat and carbohydrate were not different from the remaining children $(P>0.05)$. Their energy distribution from added sugar was significantly higher $(P=0 \cdot 0002)$, and their energy distribution from protein was significantly lower $(P=0.03)$ than those in the children who continued in the study. More detailed dropout analysis has been described previously ${ }^{(7)}$.

\section{Discussion}

In the present cluster-randomised, cross-over, school-based intervention study with Danish children aged 8-11 years, the overall diet was nutritionally improved during the period when the children were offered free school lunch and snacks based on the principles of the NND compared with their habitual diet during a school day. Other effects of the NND on health and function outcomes and economic considerations will be reported elsewhere.

Since the intervention replaced lunch packs traditionally based on cold sandwiches with hot meals, it is not surprising that the intake of bread decreased during the intervention period and the intake of potatoes increased. The increased

Table 4. Mean daily energy and macronutrient intakes in children during the control period with packed lunches and during the intervention period with New Nordic Diet (NND) lunches and the effect of the NND on energy and macronutrients compared with the control

(Mean values and standard deviations; estimates and $95 \%$ confidence intervals)

\begin{tabular}{|c|c|c|c|c|c|c|c|}
\hline \multirow[b]{2}{*}{ Energy and macronutrients } & \multicolumn{2}{|c|}{ Control ( $n$ 704) } & \multicolumn{2}{|c|}{ NND $(n 700)$} & \multicolumn{3}{|c|}{ Effect $^{*}$} \\
\hline & Mean & SD & Mean & SD & $P$ & Estimate & $95 \% \mathrm{Cl}$ \\
\hline Energy $(\mathrm{MJ} / \mathrm{d})$ & 7.5 & 1.9 & $7 \cdot 4$ & $2 \cdot 0$ & 0.44 & -50.5 & $-177 \cdot 8,76.9$ \\
\hline Energy density from food $(\mathrm{kJ} / \mathrm{g})$ & $7 \cdot 8$ & $1 \cdot 2$ & $7 \cdot 4$ & $1 \cdot 2$ & $<0.0001$ & -0.46 & $-0.56,-0.37$ \\
\hline Energy density from beverages $(\mathrm{kJ} / \mathrm{g})$ & 0.88 & 0.38 & 0.84 & 0.37 & 0.001 & -0.04 & $-0.06,-0.02$ \\
\hline Energy from fat $(\%)$ & 33 & 4 & 32 & 4 & $<0.0001$ & -0.94 & $-1.27,-0.61$ \\
\hline Energy from total carbohydrate (\%) & 52 & 5 & 52 & 5 & 0.72 & 0.07 & $-0.32,0.47$ \\
\hline Energy from added sugar (\%) & 11 & 5 & 11 & 5 & 0.56 & -0.10 & $-0.45,0.24$ \\
\hline Energy from protein (\%) & 15 & 2 & 16 & 3 & $<0.0001$ & 0.86 & $0.67,1.06$ \\
\hline Total fat $(\mathrm{g} / \mathrm{d})$ & 66 & 20 & 64 & 20 & 0.0007 & -2.39 & $-3 \cdot 77,-1.01$ \\
\hline Saturated fat $(\mathrm{g} / \mathrm{d})$ & 26 & 9 & 25 & 8 & $<0.0001$ & -1.30 & $-1.91,-0.69$ \\
\hline Monounsaturated fat (g/d) & 24 & 7 & 23 & 8 & 0.01 & -0.67 & $-1.21,-0.13$ \\
\hline Polyunsaturated fat $(\mathrm{g} / \mathrm{d})$ & 10 & 3 & 10 & 3 & 0.82 & -0.03 & $-0.26,0.20$ \\
\hline Trans-fatty acids $(\mathrm{g} / \mathrm{d})$ & 1.4 & 0.56 & 1.4 & 0.54 & 0.02 & -0.05 & $-0.09,-0.01$ \\
\hline Carbohydrate (g/day) & 237 & 61 & 236 & 65 & 0.71 & -0.81 & $-5 \cdot 1,3.48$ \\
\hline Added sugar $(\mathrm{g} / \mathrm{d})$ & 51 & 26 & 50 & 27 & 0.27 & -1.06 & $-2.96,0.83$ \\
\hline Dietary fibre $(\mathrm{g} / \mathrm{d})$ & 17 & 6 & 18 & 6 & $0.05 \dagger$ & $1.03 \ddagger$ & $1.00,1.05$ \\
\hline Protein $(\mathrm{g} / \mathrm{d})$ & 67 & 19 & 71 & 21 & $<0.0001$ & 3.37 & $1.99,4.74$ \\
\hline
\end{tabular}

*Analysed by hierarchical mixed models, controlling for random effects (child, class and school) and fixed effects (sex, grade, dietary period, BMI, season eating the NND and household education).

† Borderline significant.

$\ddagger$ Dietary fibre was $\log _{2}$ transformed; hence this estimate is expressed in percentages. 
Table 5. Median daily micronutrient intakes in children during the control period with packed lunches and during the intervention period with New Nordic Diet (NND) lunches and the effect of the NND on micronutrients compared with the control (Median values with their 10th and 90th percentiles; estimates and $95 \%$ confidence intervals)

\begin{tabular}{|c|c|c|c|c|c|c|c|c|c|}
\hline \multirow[b]{3}{*}{ Micronutrients } & \multicolumn{3}{|c|}{ Control ( $n$ 704) } & \multicolumn{3}{|c|}{ NND $(n 700)$} & & & \\
\hline & \multirow[b]{2}{*}{ Median } & \multicolumn{2}{|c|}{ Percentile } & \multirow[b]{2}{*}{ Median } & \multicolumn{2}{|c|}{ Percentile } & \multicolumn{3}{|c|}{ Effect $^{\star}$} \\
\hline & & 10 & 90 & & 10 & 90 & $P$ & Estimate & $95 \% \mathrm{Cl} \dagger$ \\
\hline Vitamin A (RE/d) & 628 & 287 & 1453 & 609 & 292 & 1193 & 0.32 & 0.98 & $0.93,1.02$ \\
\hline Vitamin D ( $\mu \mathrm{g} / \mathrm{d})$ & 1.9 & 0.98 & 5.5 & 2.39 & $1 \cdot 10$ & 11.9 & $<0.0001$ & 1.42 & $1.32,1.53$ \\
\hline Vitamin $\mathrm{E}(\alpha-\mathrm{TE} / \mathrm{d})$ & $5 \cdot 5$ & $3 \cdot 3$ & $8 \cdot 1$ & $5 \cdot 8$ & 3.5 & $9 \cdot 2$ & $<0.0001$ & 1.08 & $1.05,1.12$ \\
\hline Vitamin $B_{1}(\mathrm{mg} / \mathrm{d})$ & 1.0 & 0.7 & 1.5 & 1.0 & 0.7 & 1.5 & 0.16 & 0.98 & $0.96,1.01$ \\
\hline Vitamin $B_{2}(\mathrm{mg} / \mathrm{d})$ & 1.3 & 0.9 & $2 \cdot 0$ & 1.3 & 0.8 & $2 \cdot 1$ & 0.70 & 1.00 & $0.98,1.03$ \\
\hline Niacin (NE/d) & 22 & 14 & 31 & 23 & 15 & 33 & $<0.0001$ & 1.05 & $1.03,1.08$ \\
\hline Vitamin $B_{6}(\mathrm{mg} / \mathrm{d})$ & 1.2 & 0.8 & 1.6 & $1 \cdot 2$ & 0.8 & 1.8 & $<0.0001$ & 1.07 & $1.05,1.09$ \\
\hline Folate $(\mu \mathrm{g} / \mathrm{d})$ & 225 & 146 & 336 & 233 & 147 & 349 & 0.0006 & 1.05 & $1.02,1.07$ \\
\hline Vitamin $B_{12}(\mu \mathrm{g} / \mathrm{d})$ & 4.3 & $2 \cdot 2$ & 7.6 & 4.3 & 2.4 & 7.5 & 0.07 & 1.03 & $1.00,1.07$ \\
\hline Vitamin $\mathrm{C}(\mathrm{mg} / \mathrm{d})$ & 70 & 36 & 132 & 76 & 36 & 143 & 0.0003 & 1.08 & $1.04,1.13$ \\
\hline $\mathrm{Ca}(\mathrm{mg} / \mathrm{d})$ & 845 & 533 & 1258 & 872 & 523 & 1366 & 0.06 & 1.02 & $1.00,1.05$ \\
\hline$P(\mathrm{mg} / \mathrm{d})$ & 1195 & 815 & 1680 & 1249 & 822 & 1799 & $<0.0001$ & 1.04 & $1.02,1.06$ \\
\hline $\mathrm{Mg}(\mathrm{mg} / \mathrm{d})$ & 248 & 173 & 351 & 258 & 170 & 372 & 0.002 & 1.03 & $1.01,1.05$ \\
\hline $\mathrm{Fe}(\mathrm{mg} / \mathrm{d})$ & 8.3 & 5.5 & 12 & 8.7 & 5.7 & 12 & $<0.0001$ & 1.05 & $1.03,1.07$ \\
\hline $\mathrm{Zn}(\mathrm{mg} / \mathrm{d})$ & $9 \cdot 2$ & $6 \cdot 1$ & 13 & 9.4 & $6 \cdot 0$ & 14 & $0.05 \ddagger$ & 1.02 & $1.00,1.04$ \\
\hline I $(\mu \mathrm{g} / \mathrm{d})$ & 170 & 109 & 283 & 194 & 112 & 318 & $<0.0001$ & $1 \cdot 11$ & $1.08,1.15$ \\
\hline $\operatorname{Se}(\mu \mathrm{g} / \mathrm{d})$ & 36 & 23 & 56 & 38 & 24.2 & 60 & $<0.0001$ & 1.05 & $1.03,1.08$ \\
\hline $\mathrm{Na}(\mathrm{g} / \mathrm{d})$ & 2.9 & 1.9 & 4.0 & $2 \cdot 8$ & 1.9 & 4.0 & 0.07 & 0.98 & $0.96,1.00$ \\
\hline$K(g / d)$ & $2 \cdot 3$ & 1.6 & 3.3 & $2 \cdot 6$ & 1.6 & 3.6 & $<0.0001$ & 1.08 & $1 \cdot 06,1 \cdot 11$ \\
\hline
\end{tabular}

$\mathrm{RE}$, retinol equivalent; TE, tocopherol equivalent; $\mathrm{NE}$, niacin equivalent.

*Analysed by hierarchical mixed models, controlling for random effects (child, class and school) and fixed effects (sex, grade, dietary period, BMI, season eating the NND and household education).

†All micronutrients were $\log _{2}$ transformed; hence estimates are expressed in percentages.

$\ddagger$ Borderline significant.

fish and vegetable intake was in agreement with the principles of the NND ${ }^{(35)}$, but this was not the case for the higher intake of cheese during the NND period than in the control period. This could be a consequence of using cheese as a flavouring, for example with potatoes and vegetables, and as a supplement to soups. Moreover, skyr (an Icelandic cultured low-fat, highprotein dairy product) was used in several sauces and dressings and was categorised as cheese (similar to curd cheese). The increased fish intake was mirrored in an increased intake of vitamin $\mathrm{D}$ and iodine, and the increased potato intake was mirrored in an increased intake of K. Fruit is an important part of the NND, and fruit (mainly apples, pears and dried berries) was offered to the children every day at school, either as part of the lunch or as an afternoon take-away snack. It was therefore unexpected that the reported fruit intake during the NND period was not greater than that in the control period, and it must be assumed that the fruit was either not eaten or not registered, or that fruit was already a part of the packed lunch brought from home during the control period. Fruit intake has been a focus point in Danish schools for several years in the form of, for example, 'fruit breaks ${ }^{\text {,(44), }}$, and the fruit intake among Danish children is in the high end compared with other European countries ${ }^{(45)}$. Some other intervention studies have focused on fruit and vegetables, but only improved the fruit intake, not the vegetable intake ${ }^{(30)}$, so although the fruit intake was not improved in the present study, it was gratifying that the intake of vegetables increased. The intake of fats decreased and the fat quality improved during the NND period compared with the control period, and this result was in accordance with the principles of the NND, which aim to fulfil the official nutrition recommendations ${ }^{(34)}$. No differences were seen in the overall energy intake between the NND and control periods; however, the aim of the OPUS School Meal Study was not weight loss. The energy intake from fat was also reduced and the energy intake from protein increased during the NND intervention period. The total energy intake in the children taking part $(7 \cdot 4-7 \cdot 5 \mathrm{MJ} / \mathrm{d})$ was lower than the data from a similar age group in the DANSDA $2003-8(8.4 \mathrm{MJ} / \mathrm{d})^{(3)}$, but higher than that found in the OPUS pilot study $(7 \cdot 2 \mathrm{MJ} / \mathrm{d})$, when flu was prevalent during the dietary assessment period $^{(39)}$. However, the energy distributions of the dietary intakes during both the NND and control periods were similar to both the National Survey and the pilot study ${ }^{(3,39)}$. It was found that the intervention had no impact on the total intake of added sugar (and carbohydrate). It can be speculated that any changes in the dietary intake during school hours might have been compensated for outside school hours and thus be responsible for this lack of difference ${ }^{(18)}$. Further analyses are needed to evaluate whether and how consumption of NND school meals may have an impact on food choices outside of school hours.

The differences in the intakes of some nutrients and food groups between the NND intervention period and the control period were small, and it can be questioned whether a 3-8\% increase in the intake of some micronutrients has relevant nutritional beneficial effects for apparently healthy Danish children. However, the overall quality of the diet was improved (e.g. more fish and vegetables and less saturated fat). 
A reduced risk of CVD has been suggested among adults with an increased intake of fruit and vegetables, or an increased intake of fish, or a reduced intake of saturated fat ${ }^{(46-48)}$. The long-term implications and improvements in health are difficult to predict, but consumptions of traditional Nordic foods have been associated with reduced mortality in adults, and randomised trials in high-risk individuals have shown improvements in the risk markers of $\mathrm{CVD}^{(49,50)}$. Although some of the changes are small, they are all in the direction of a diet and nutritional improvement. Moreover, the positive effects shown are the result of just one lunch meal and two snack meals eaten only on weekdays over 3 months, and the effects are therefore 'diluted' by food eaten outside school. This school meal intervention based on the principles of the NND ${ }^{(35)}$ introduced many new foods and flavours to the children. Additionally, eating foods from one's own geographical region may have environmental implications by reducing the burden of transport and production ${ }^{(35)}$.

The differences found between the $3 \mathrm{rd}$ and 4 th grade children may be explained by the fact that children in the 3rd grade are often supervised by teachers during most activities during the day, while this is not the case for many of the 4th graders. During the OPUS School Meal Study, observations by the researchers present at the schools strongly suggested that the 3rd graders followed the guidelines of the teachers and the encouragements of the chefs and other kitchen staff to taste the food, whereas the 4th graders were often less guided by the teachers and typically in a hurry to get outside to play after the lunch break. Moreover, the 3rd graders may have received more parental aid with the dietary assessment in the WebDASC than the 4th graders. Sex differences may be explained by a combination of a slightly higher body weight $(700 \mathrm{~g})$ and a relatively higher proportion of lean body mass in boys.

The NND school meals were free and inevitably cheaper than the packed lunches brought from home. The present study was thus an artificial situation designed for research purposes, where the focus was on testing the effect of the NND on multiple outcomes. If a school meal programme is rolled out in Denmark, meals will not be free. However, the price could be differentiated depending on the income of the parents, as seen at a school meal project in Copenhagen ${ }^{(51)}$. Whether this price principle could be employed over the entire country is uncertain. The economic aspects of a school meal programme are crucial for its success in real life, and the costs of NND school meals will be addressed separately. However, schools provide an excellent setting for public health nutritional interventions, because they give the potential to reach all children regardless of ethnic and socioeconomic background.

To our knowledge, no randomised controlled trial has assessed the impact of introducing a full-meal concept prepared by chefs and covering lunch and snacks during the school day, including the measurement of children's dietary and nutrient intake using a Web-based dietary assessment tool especially developed for children. However, good intentions with high-quality food prepared by professional chefs based on new recipes and ingredients and the use of a child-friendly tool to assess the intake will not lead to any improvements in the diet, health and development of the children if the foods are not consumed by the children ${ }^{(52)}$. Several factors are known to influence the intake of food, including adequate time to eat the food, a feeling of ownership of the food, the presentation of the food, food being recognisable to the children and a pleasant eating environment ${ }^{(53)}$. In the OPUS School Meal Study, several actions were taken to meet these challenges. The lunch break was extended during the NND period from the normal 15 to $20-25 \mathrm{~min}$. Small groups of children took part in the cooking every day; they presented the foods to their classmates and helped with the serving of the food, in order to create a feeling of ownership of the food. Moreover, the children were encouraged to taste all the food served and to have a reasonable plate distribution between meat/fish, vegetables and starchy foods. The weekly menu of the season was repeated every 3 weeks, which increased the likelihood of the food being recognisable to the children. Finally, the food was served at set tables in the classroom or in a common eating area depending on the facilities of the schools.

The general strengths and limitations of the study have been described elsewhere ${ }^{(7)}$. The novel interactive Web-based dietary assessment tool developed for children was a help for the families who took part, because they found it relatively easy to use $^{(37)}$. However, one limitation was that some of the families had no access to their own computer. During the lunch breaks, a lot of effort was put into motivating the children to try new foods and dishes. However, one limitation was not having adult 'food ambassadors' encouraging the children to eat the food at every school in the same way. The pilot study was conducted during the winter season, and the recipes used in the pilot study therefore included winterseason recipes. However, the main OPUS School Meal Study was conducted over three seasons (autumn, winter and spring), and one possible limitation of the study was that the autumn- and spring-season recipes had not been tested on a large scale beforehand. The eating environment during the NND period was not the same as that of the control period, favouring the NND meals (longer lunch break and nicer eating environment). Finally, since NND meals were very different from packed lunch, 3 months might not have been enough time to familiarise the children to the NND. Under- and over-reporting of energy intake can affect dietary surveys ${ }^{(54)}$. In the present study, the effect of the NND with regard to reducing intakes of monounsaturated fat, transfatty acids and fats became non-significant after adjusting for the reporting status (OR, UR and AR), which could indicate differential reporting of fat intake for the three types of reporters. The children who dropped out of the present study did not differ from those who continued in the study with regard to their average total energy intake, but they did have a higher energy distribution from added sugar and a lower energy distribution from protein. This emphasises the importance of schools as a setting to reach all children regardless of their nutritional background in order to help the children who are most in need ${ }^{(55)}$. 
In conclusion, the present study showed that the overall dietary intake at the food and nutrient levels was improved among children aged 8-11 years when their habitual packed school lunches were replaced by school meals following the principles of the NND.

\section{Acknowledgements}

The authors thank all the children and their parents/guardians for their participation in the study. The authors thank research dietitian Karin Hess Ygil for checking and calculating the nutrients in all recipes and meals, and data manager Karsten Kørup for making the dietary intake calculations.

The present study was supported by a grant from the Nordea Foundation (grant no. 02-2010-0389). The funder had no role in the design, analysis or writing of this article.

The authors' contributions are as follows: A. B.-J., C. T. D., A. A., K. F. M. and I. T. designed the study; R. A., A. B.-J. and I. T. formulated the research questions; R. A. and M. E. collected the dietary intake data; S.-M. D., C. T. D. and A. V. T. contributed to the collection of the other data; E. W. A. undertook the statistical analyses in cooperation with R. A., A. B.-J. and I. T.; T. C. undertook the calculations of the dietary intake data in cooperation with R. A. and M. E.; R. A. wrote the manuscript. All authors read and approved the final content of the manuscript.

A. A. is a consultant or member of the advisory board for a number companies, including BioCare Copenhagen, Denmark; Global Dairy Platform, USA; Jenny Craig, USA; McCain Foods Limited, USA; McDonald's, USA; Pathway Genomics Corporation, USA; and S-Biotek, Denmark. The rest of the authors have no conflicts of interest to declare.

\section{References}

1. Koplan JP, Liverman CT \& Kraak VI (2005) Extent and Consequences of Childhood Obesity. Preventing Childhood Obesity: Health in the Balance, pp. 54-78 [Committee on Prevention of Obesity in Children and Youth, editor]. Washington, DC: The National Academies Press.

2. World Health Organisation (2003) Diet, Nutrition and the Prevention of Chronic Diseases. Joint WHO/FAO Expert Consultation. WHO Technical Report Series no. 916. Geneva: WHO.

3. Pedersen AN, Fagt S, Groth MV, et al. (2010) Dietary Habits in Denmark 2003-2008 (in Danish). Søborg: Division of Nutrition, National Food Institute, Technical University of Denmark.

4. Christensen LM, Kørup K, Trolle E, et al. (2012) Dietary Habits of Children and Adolescents 2005-2008 (in Danish). Søborg: Division of Nutrition, National Food Institute, Technical University of Denmark.

5. Hoppe C, Biltoft-Jensen A, Trolle E, et al. (2009) Dietary Habits of Danish 8- to 10-Year-Old Children. Søborg: Division of Nutrition, National Food Institute, Technical University of Denmark.

6. Evans CEL, Greenwood DC, Thomas JD, et al. (2010) A crosssectional survey of children's packed lunches in the UK: food- and nutrient-based results. I Epidemiol Community Health 64, 977-983.
7. Damsgaard CT, Dalskov SM, Petersen RA, et al. (2012) Design of the OPUS School Meal Study: a randomised controlled trial assessing the impact of serving school meals based on the New Nordic Diet. Scand I Public Health 40, 693-703.

8. Lissau I, Hesse U, Juhl M, et al. (2006) Food and Physical Activity in Preschools, Schools and After School Institutions (in Danish). København: Statens Institut for Folkesundhed.

9. Lavelle HV, Mackay DF \& Pell JP (2012) Systematic review and meta-analysis of school-based interventions to reduce body mass index. J Public Health (Oxf) 34, 360-369.

10. Story M, Nanney MS \& Schwartz MB (2009) Schools and obesity prevention: creating school environments and policies to promote healthy eating and physical activity. Milbank Q 87, 71-100.

11. Groth MV, Christensen LM \& Knudsen VK (2013) Social Differences in Children's Dietary Habits, Physical Activity and Overweight, and Adults' Dietary Habits. Søborg: Division of Nutrition, National Food Institute, Technical University of Denmark.

12. Morrison JA, Friedman LA, Wang P, et al. (2008) Metabolic syndrome in childhood predicts adult metabolic syndrome and type 2 diabetes mellitus 25 to 30 years later. $J$ Pediatr 152, 201-206

13. Magarey AM, Daniels LA, Boulton TJ, et al. (2003) Predicting obesity in early adulthood from childhood and parental obesity. Int J Obes Relat Metab Disord 27, 505-513.

14. Freedman DS, Khan LK, Serdula MK, et al. (2004) Interrelationships among childhood BMI, childhood height, and adult obesity: the Bogalusa Heart Study. Int J Obes Relat Metab Disord 28, 10-16.

15. De Bourdeaudhuij I, Van Cauwenberghe E, Spittaels H, et al. (2011) School-based interventions promoting both physical activity and healthy eating in Europe: a systematic review within the HOPE project. Obes Rev 12, 205-216.

16. Grydeland M, Bjelland M, Anderssen SA, et al. (2013) Effects of a 20-month cluster randomised controlled school-based intervention trial on BMI of school-aged boys and girls: the HEIA study. Br J Sports Med (Epublication ahead of print version 27 April 2013).

17. Hoppu U, Lehtisalo J, Kujala J, et al. (2010) The diet of adolescents can be improved by school intervention. Public Health Nutr 13, 973-979.

18. Donnelly JE, Jacobsen DJ, Whatley JE, et al. (1996) Nutrition and physical activity program to attenuate obesity and promote physical and metabolic fitness in elementary school children. Obes Res 4, 229-243.

19. Foster GD, Linder B, Baranowski T, et al. (2010) A schoolbased intervention for diabetes risk reduction. $N$ Engl J Med 363, 443-453.

20. Sahota P, Rudolf MC, Dixey R, et al. (2001) Randomised controlled trial of primary school based intervention to reduce risk factors for obesity. BMJ 323, 1029-1032.

21. Luepker RV, Perry CL, McKinlay SM, et al. (1996) Outcomes of a field trial to improve children's dietary patterns and physical activity. The Child and Adolescent Trial for Cardiovascular Health. CATCH collaborative group. JAMA $\mathbf{2 7 5}$, $768-776$.

22. Sallis JF, McKenzie TL, Conway TL, et al. (2003) Environmental interventions for eating and physical activity: a randomized controlled trial in middle schools. Am J Prev Med 24, 209-217.

23. Caballero B, Clay T, Davis SM, et al. (2003) Pathways: a school-based, randomized controlled trial for the prevention of obesity in American Indian schoolchildren. Am J Clin Nutr 78, 1030-1038. 
24. Osganian SK, Ebzery MK, Montgomery DH, et al. (1996) Changes in the nutrient content of school lunches: results from the CATCH Eat Smart Food Service Intervention. Prev Med 25, 400-412.

25. Summerbell CD, Waters E \& Edmunds LD, et al. (2005) Interventions for preventing obesity in children. The Cochrane Database of Systematic Reviews, CD001871.

26. Jaime PC \& Lock K (2009) Do school based food and nutrition policies improve diet and reduce obesity? Prev Med 48, 45-53.

27. Shaya FT, Flores D, Gbarayor CM, et al. (2008) School-based obesity interventions: a literature review. J Sch Health $\mathbf{7 8}$, 189-196.

28. Waters E, de Silva-Sanigorski A \& Hall BJ, et al. (2011) Interventions for preventing obesity in children. The Cochrane Database of Systematic Reviews, CD001871.

29. Kristjansdottir AG, Johannsson E \& Thorsdottir I (2010) Effects of a school-based intervention on adherence of 7-9-year-olds to food-based dietary guidelines and intake of nutrients. Public Health Nutr 13, 1151-1161.

30. Evans CE, Christian MS, Cleghorn CL, et al. (2012) Systematic review and meta-analysis of school-based interventions to improve daily fruit and vegetable intake in children aged 5 to 12 y. Am J Clin Nutr 96, 889-901.

31. Te Velde SJ, Brug J, Wind M, et al. (2008) Effects of a comprehensive fruit- and vegetable-promoting school-based intervention in three European countries: the Pro Children Study. Br J Nutr 99, 893-903.

32. Knai C, Pomerleau J, Lock K, et al. (2006) Getting children to eat more fruit and vegetables: a systematic review. Prev Med 42, 85-95.

33. Cohen JF, Smit LA, Parker E, et al. (2012) Long-term impact of a chef on school lunch consumption: findings from a 2-year pilot study in Boston middle schools. J Acad Nutr Diet 112, 927-933.

34. Nordic Nutrition Recommendations (2004) Integrating Nutrition and Physical Activity, 4th ed. Copenhagen: Nordic Council of Ministers.

35. Mithril C, Dragsted LO, Meyer C, et al. (2012) Guidelines for the New Nordic Diet. Public Health Nutr 15, 1941-1947.

36. Mithril C, Dragsted LO, Meyer C, et al. (2013) Dietary composition and nutrient content of the New Nordic Diet. Public Health Nutr 16, 777-785.

37. Biltoft-Jensen A, Trolle E, Christensen T, et al. (2012) WebDASC: a web-based dietary assessment software for 8-11-year-old Danish children. J Hum Nutr Diet 27, Suppl. 1, 43-53.

38. Biltoft-Jensen A, Bysted A, Trolle E, et al. (2012) Evaluation of Web-based Dietary Assessment Software for Children: comparing reported fruit, juice and vegetable intakes with plasma carotenoid concentration and school lunch observations. Br J Nutr 110, 186-195.

39. Biltoft-Jensen A, Matthiessen J, Rasmussen LB, et al. (2009) Validation of the Danish 7-day pre-coded food diary among adults: energy intake $v$. energy expenditure and recording length. Br J Nutr 102, 1838-1846.

40. Saxholt E, Christensen T, Møller A, et al. (2008) Danish Food Composition Databank, Revision 7. Søborg: Division of Nutrition, National Food Institute, Technical University of Denmark. http:/www.foodcomp.dk/
41. Black AE (2000) Critical evaluation of energy intake using the Goldberg cut-off for energy intake:basal metabolic rate. A practical guide to its calculation, use and limitations. Int J Obes Relat Metab Disord 24, 1119-1130.

42. Henry CJK (2005) Basal metabolic rate studies in humans: measurement and development of new equations. Public Health Nutr 8, 1133-1152.

43. Min Y \& Agresti A (2002) Modeling nonnegative data with clumping at zero: a survey. J Iranian Statistical Society 1, $7-33$.

44. Hoppe C, Iversen JD, Niemann GL, et al. (2012) Evaluering af den danske EU-finansierede skolefrugtordning 2010/11 kvantitative og kvalitative aspekter (Evaluation of the Danish EU-Funded School Fruit Scheme 2010/11 - Quantitative and Qualitative Aspects) (in Danish). Søborg: Division of Nutrition, National Food Institute, Technical University of Denmark.

45. Yngve A, Wolf A, Poortvliet E, et al. (2005) Fruit and vegetable intake in a sample of 11 -year-old children in 9 European countries: the pro children cross-sectional survey. Ann Nutr Metab 49, 236-245.

46. Hartley L, Igbinedion E \& Holmes J, et al. (2013) Increased consumption of fruit and vegetables for the primary prevention of cardiovascular diseases. The Cochrane Database of Systematic Reviews, issue 6.

47. Hooper L, Summerbell CD \& Thompson R, et al. (2012) Reduced or modified dietary fat for preventing cardiovascular disease. The Cochrane Database of Systematic Reviews, issue 5.

48. Musa-Veloso K, Binn MA, Kocenas A, et al. (2011) Impact of low v. moderate intakes of long-chain $n$-3 fatty acids on risk of coronary heart disease. Br J Nutr 106, 1129-1141.

49. Adamsson V, Reumark A, Fredriksson IB, et al. (2011) Effects of a healthy Nordic diet on cardiovascular risk factors in hypercholesterolaemic subjects: a randomised controlled trial (NORDIET). J Intern Med 269, 150-159.

50. de Mello VDF, Schwab U, Kolehmainen M, et al. (2011) A diet high in fatty fish, bilberries and wholegrain products improves markers of endothelial function and inflammation in individuals with impaired glucose metabolism in a randomised controlled trial: the Sysdimet study. Diabetologia 54, 2755-2767.

51. Sylow M (2013) Skolemadssatsningen $i \mathrm{KBH}$, EAT 20072012 (The School Meals Venture in Copenhagen, EAT 2007-2012) (in Danish). København: Københavns Madhus.

52. Gatenby LA (2011) Children's nutritional intake as part of the Eat Well Do Well scheme in Kingston-upon-Hull - a pilot study. Nutr Bull 36, 87-94.

53. Story M, Neumark-Sztainer D \& French S (2002) Individual and environmental influences on adolescent eating behaviors. I Am Diet Assoc 102, S40-S51.

54. Glynn L, Emmett P \& Rogers I (2005) Food and nutrient intakes of a population sample of 7 -year-old children in the south-west of England in 1999/2000 - what difference does gender make? J Hum Nutr Diet 18, 7-19.

55. Bauer KW, Neumark-Sztainer D, Hannan PJ, et al. (2011) Relationships between the family environment and schoolbased obesity prevention efforts: can school programs help adolescents who are most in need? Health Educ Res 26, 675-688. 